\title{
TIME RESOLVED TRANSIENT ABSORPTION PROBING OF A LASER PLASMA
}

\author{
M. HEMICI, S. MOTTIN, M. BON, J.-Y. RONCIN and P. LAPORTE \\ Laboratoire Traitement du Signal et Instrumentation and Ecole Nationale Supérieure des Mines, \\ 158 bis cours Fauriel, F-42023 Saint-Etienne cedex, France
}

During the last two decades dense rare gases have attracted a great number of workers due to their potentiality as laser media. In this respect a detailed knowledge of plasma kinetics is of great importance. A recent study of kinetics and decay processes in argon has shown that the $4 \mathrm{~s}$ atomic levels act as decay steps [1]. The present communication reports on a method allowing the kinetic study of an argon plasma by transient visible absorption spectroscopy from the first 4s-level manifold.

The plasma is created by focusing a pulsed YAG laser in argon at variable pressure, typically in the atmospheric range. The probe beam is obtained by irradiating with a second YAG laser a dye cell operated in the broad band regime [2]. The light is analyzed with a $2.5-\mathrm{m}$ Ebert spectrometer equipped with an EG\&G optical multichannel analyzer (OMA).

The light from the plasma and that from the dye cell are viewed by two photodiodes whose signals are sent to an electronic monitor so that the time delay between the plasma and the probe beam can be adjusted from a few ns to a few $\mu \mathrm{s}$. It is observed that when the time delay is increased the well known background absorption decreases and gives way to discrete absorption lines corresponding to transitions starting from the first excited atomic levels. Discrete absorption is the strongest for a delay in the 100ns range, depending on pressure, and decreases afterwards.

Fig. 1 shows several transmission curves in argon at $10^{5} \mathrm{~Pa}$ for time delays from 0 to 70 ns. Lines A and B correspond, respectively, to transitions $4 \mathrm{~s}[3 / 2]_{1} \rightarrow-5 \mathrm{p}[1 / 2]_{0}$ and $4 \mathrm{~s}[3 / 2]_{2}$ $-5 \mathrm{p}[5 / 2]_{3}$

The method, which is of wide applicability, will be first devoted to study kinetics and spectroscopy of rare gases.

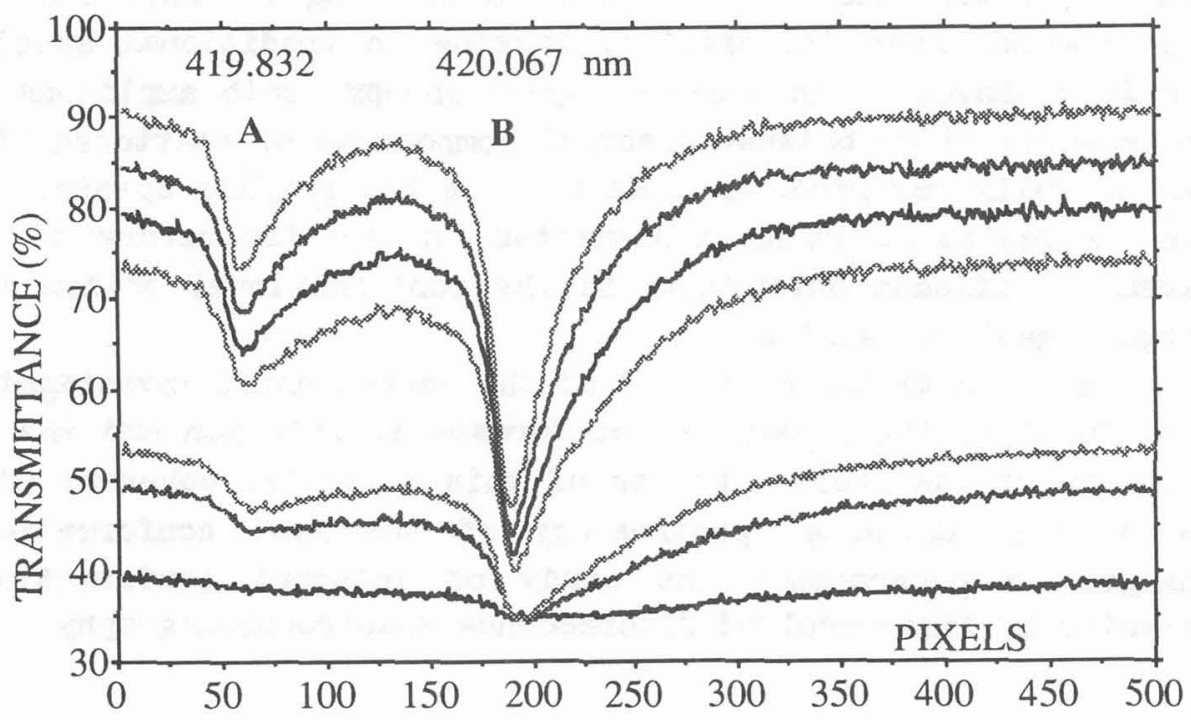

[1] P. Moutard, P. Laporte, J.-L. Subtil, N. Damany and H. Damany, J. Chem. Phys. 87. $4576(1987)$

[2] H. Damany, N. Damany and J.-Y. Roncin, J. Phys. E 16, 469 (1983) 